\title{
Lifestyle changes and the risk of developing endometrial and ovarian cancers: opportunities for prevention and management
}

This article was published in the following Dove Press journal:

International Journal of Women's Health

23 May 2016

Number of times this article has been viewed

\author{
Anna L Beavis ${ }^{1, *}$ \\ Anna Jo Bodurtha Smith ${ }^{2, *}$ \\ Amanda Nickles Fader' \\ 'Department of Gynecology and \\ Obstetrics, The Kelly Gynecologic \\ Oncology Service, Johns Hopkins \\ Medicine, Baltimore, MD, ${ }^{2}$ Harvard \\ Medical School, Boston, MA, USA \\ *These authors contributed equally \\ to this work
}

\begin{abstract}
Modifiable lifestyle factors, such as obesity, lack of physical activity, and smoking, contribute greatly to cancer and chronic disease morbidity and mortality worldwide. This review appraises recent evidence on modifiable lifestyle factors in the prevention of endometrial cancer (EC) and ovarian cancer (OC) as well as new evidence for lifestyle management of EC and OC survivors. For EC, obesity continues to be the strongest risk factor, while new evidence suggests that physical activity, oral contraceptive pills, and bariatric surgery may be protective against EC. Other medications, such as metformin and nonsteroidal anti-inflammatory drugs, may be protective, and interventional research is ongoing. For OC, we find increasing evidence to support the hypothesis that obesity and hormone replacement therapy increase the risk of developing OC. Oral contraceptive pills are protective against OC but are underutilized. Dietary factors such as the Mediterranean diet and alcohol consumption do not seem to affect the risk of either OC or EC. For EC and OC survivors, physical activity and weight loss are associated with improved quality of life. Small interventional trials show promise in increasing physical activity and weight maintenance for EC and OC survivors, although the impact on long-term health, including cancer recurrence and overall mortality, is unknown. Women's health providers should integrate counseling about these modifiable lifestyle factors into both the discussion of prevention for all women and the management of survivors of gynecologic cancers.
\end{abstract}

Keywords: lifestyle, prevention, endometrial cancer, ovarian cancer, gynecologic cancer, obesity

\section{Introduction}

Obesity, inactivity, and poor diet contribute to $\sim 20 \%$ of annual mortality worldwide. ${ }^{1}$ Although tobacco consumption has historically driven lifestyle-related mortality, the epidemic of obesity (defined as body mass index [BMI] $\geq 30 \mathrm{~kg} / \mathrm{m}^{2}$ ) and associated sedentary Western lifestyle has led to a rising incidence of obesity-related comorbidities and cancers in high-income countries since the 1980s. ${ }^{2}$ Approximately half of all cancers are associated with modifiable risk factors. ${ }^{3}$ In particular, cancers of the endometrium (uterine), breast, colon, prostate, and kidney are obesity driven. ${ }^{4} \mathrm{~A}$ recent study suggested that, in the last decade, $25 \%$ of all cancers diagnosed worldwide could have been prevented if obesity rates had not increased. ${ }^{5}$ Low- and middle-income countries are increasingly burdened by the obesity epidemic. The dangers of obesity and a sedentary lifestyle have become pervasive with a staggering $60 \%$ of adults globally (representing 3 billion people) expected to be overweight or obese by 2030 . $^{1,6}$

Among the most obesity-driven malignancies are the gynecologic cancers, particularly endometrial cancer (EC). The worldwide obesity epidemic may fuel an increase
Correspondence: Amanda Nickles Fader The Kelly Gynecologic Oncology Service, Johns Hopkins Medicine, 600 North Wolfe Street, Phipps 287, Baltimore, MD 21287, USA

Tel + I 4109558240

Email afaderl@jhmi.edu
International Journal of Women's Health 2016:8 I5I-167

(c) (i) (2) () 2016 Beavis et al. This work is published and licensed by Dove Medical Press Limited. The full terms of this license are avalable at https://www.dovepress.com/terms.php cc. hereby accept the Terms. Non-commercial uses of the work are permitted without any further permisision from Dove Medical Press Limited, provided the work is properly attributed. For permission for commercial use of this work, please see paragraphs 4.2 and 5 of our Terms (https://www. doverperess.com/terms.php).

5 I you
Dovepress

http://dx.doi.org/10.2147/IJWH.S88367 
Table I American Cancer Society recommendations for cancer prevention and survivorship

\begin{tabular}{|c|c|c|}
\hline & Cancer prevention & Cancer survivorship \\
\hline \multirow[t]{6}{*}{ Physical activity } & Adopt a physically active lifestyle & Adopt a physically active lifestyle \\
\hline & Engage in at least I 50 minutes of moderate intensity or & Engage in at least I 50 minutes of physical activity each \\
\hline & 75 minutes of vigorous intensity activity each week & week \\
\hline & Limit sedentary behavior, such as sitting down, watching & Do strength training exercises at least 2 days each week \\
\hline & television, or other forms of screen-based entertainment & Avoid inactivity \\
\hline & & $\begin{array}{l}\text { Return to normal activities as soon as possible following } \\
\text { diagnosis }\end{array}$ \\
\hline \multirow[t]{3}{*}{ Weight management } & Achieve and maintain a healthy weight throughout life & Achieve and maintain a healthy weight \\
\hline & Be as lean as possible without being underweight & Limit consumption of high calorie foods and beverages \\
\hline & Avoid excess weight gain at all ages & $\begin{array}{l}\text { Increase physical activity to promote weight loss if } \\
\text { overweight or obese }\end{array}$ \\
\hline \multirow[t]{5}{*}{ Diet } & Consume a healthy diet, with an emphasis on plant foods & Consume a healthy diet \\
\hline & Limit consumption of processed meat or red meat & Achieve a diet pattern that is high in vegetables, fruits, \\
\hline & Eat at least 2.5 cups of vegetables and fruits each day & and whole grains \\
\hline & Choose whole grains over refined grain products & Follow the American Cancer Society guidelines for diet \\
\hline & Limit alcohol consumption to I drink or less per day (for women) & for cancer prevention \\
\hline
\end{tabular}

in EC, one of the most adipose-sensitive malignancies. Obesity also impacts EC survivorship, as survivors face great morbidity and mortality from obesity-related cardiovascular disease, ${ }^{7}$ and obese survivors have much higher cancerspecific mortality rates. ${ }^{8}$ Simultaneously, the incidence of ovarian cancer $(\mathrm{OC})$, the deadliest of gynecologic malignancies, may increase as the baby boomer population ages and life expectancy increases. ${ }^{9}$ Understanding the opportunities to prevent cancer and optimize the quality of life (QoL) for survivors is critical.

Moreover, for those diagnosed with nongynecologic cancers, research shows that lifestyle and pharmacologic interventions reduce cancer incidence. For example, maintenance of a healthy weight and adhering to a Mediterranean diet reduces the risk of breast cancer, ${ }^{10}$ and taking aspirin daily reduces the risk of colon cancer. ${ }^{11}$ Table 1 provides the American Cancer Society (ACS) recommendations for weight, diet, and physical activity related to cancer prevention and survivorship. ${ }^{12,13}$

In this review, we synthesize recent advances in understanding the role of modifiable lifestyle factors, such as obesity, in the prevention and management of EC and OC. We highlight the opportunities for lifestyle intervention in both primary prevention and cancer survivorship, including exciting new advances in chemoprevention and prophylactic surgery.

\section{Opportunities for prevention of EC Background}

In the US alone, there were an estimated 50,000 new cases of EC and >10,000 EC-related deaths in 2015. ${ }^{14}$ Obesity and sedentary behavior significantly contribute to risk of EC, specifically for type 1 (estrogen dependent) EC. ${ }^{15}$ In obese persons, excess adipocytes convert androgens to estradiol, which stimulates endometrial proliferation, leading to hyperplasia and ultimately cancer. ${ }^{16}$ Insulin resistance and diabetes, also highly associated with obesity, have independently been implicated in EC pathogenesis and are additional risk factors. ${ }^{17}$

\section{Lifestyle prevention}

\section{Obesity and physical activity}

Approximately $50 \%$ of all new diagnoses of EC are attributable to obesity alone. ${ }^{18}$ Obese women have 2.4-4.5 times the risk of being diagnosed with EC compared with normalweight women with a dose-response relationship between obesity and EC risk. ${ }^{19-21}$ Even after adjustment for other risk factors (eg, smoking, oral contraceptive pill [OCP] use, hormone replacement therapy [HRT] use, and parity), an obese woman with BMI $\geq 40 \mathrm{~kg} / \mathrm{m}^{2}$ has seven times the odds of developing type $1 \mathrm{EC}$ compared to a normal-weight woman. ${ }^{21}$ Additionally, the obesity epidemic appears to have increased EC diagnoses in younger women: incidence rates in women aged $<50$ years increased by $2 \%$ each year from 1992 to $2012 .^{22}$

There are few studies evaluating intentional weight loss and EC risk. A large prospective cohort study found a small, nonsignificant reduction in risk with intentional weight loss of at least 20 pounds (relative risk $[R R]=0.96,95 \%$ confidence interval [CI $] 0.61-1.52) .{ }^{23}$ More extreme weight loss as a result of bariatric surgery does significantly reduce EC risk (see "Surgical prevention" section). ${ }^{24}$ However, this weight loss needs to be sustained, as both weight cycling (losing 
and regaining weight repeatedly) and adult weight gain have been associated with increased EC risk. ${ }^{25,26}$

For exercise, two meta-analyses of 20 cohort and casecontrol studies have demonstrated a $20 \%-30 \%$ reduction in EC risk in women who report moderate or high intensity exercise compared to nonexercisers. ${ }^{27,28}$ The Nurses' Health Study, a large prospective cohort study started in 1976, demonstrated a temporal effect of exercise on EC risk: women who reported recent high-intensity exercise had a $35 \%$ reduced risk of EC compared to those who did not perform any vigorous activity $(\mathrm{RR}=0.65,95 \% \mathrm{CI} 0.47-0.88$ ). Additionally, daily walking in otherwise sedentary women reduces risk..$^{29}$ Another large cohort study, the ACS Prevention Study II Nutrition, found reduced EC risk with physical activity only in overweight or obese women, suggesting that women at the highest risk may glean the most benefit. ${ }^{30}$

\section{Diet}

Several studies have examined the relationship between diet and $\mathrm{EC}$ risk. In the dietary modification randomized controlled trial (RCT) of the Women's Health Initiative, postmenopausal women randomized to a low-fat diet rich in fruits, vegetables, and grains showed no difference in EC incidence after an average follow-up of 8 years. ${ }^{31}$ Although case-control studies suggest that the Mediterranean diet may be associated with a decreased risk of EC, ${ }^{32}$ prospective data from over 84,000 women in the Women's Health Initiative cohort study demonstrated no risk difference..$^{33}$ In contrast, diets with high glycemic loads increased EC risk by up to $20 \%$ in two large meta-analyses of cohort and case-control studies ( $\mathrm{RR}=1.2,95 \%$ CI $1.06-1.37^{34}$ and $95 \%$ CI $1.09-1.33^{35}$ ). A meta-analysis found no effect of dairy on EC risk. ${ }^{36}$

\section{Coffee, tea, alcohol, and other beverages}

Coffee consumption may lower EC risk: a meta-analysis of 13 cohort studies found a dose-response relationship and an overall reduced risk of $\mathrm{EC}$ with coffee consumption $(\mathrm{RR}=0.80$, 95\% CI $0.74-0.86$ for highest vs lowest coffee drinkers). ${ }^{37}$ Similar reductions have been noted with green tea consumption, but not black tea. ${ }^{38}$ For alcohol, a meta-analysis of six cohort and 14 case-control studies found no association with EC. ${ }^{39}$ Sugar-sweetened beverages, on the other hand, may increase the risk of type $1 \mathrm{EC}$ independent of BMI, as demonstrated in one case-control study ( $\mathrm{RR}=1.78,95 \%$ CI $1.31-2.40) .{ }^{40}$

\section{Smoking}

Smoking decreases the risk of EC, perhaps through antiestrogenic effects. In a meta-analysis of ten cohort studies, the risk was reduced by $19 \%$ (95\% CI $0.74-0.88) .{ }^{41}$ However, given many known negative health consequences of smoking, it cannot be recommended for EC prevention. ${ }^{2}$

\section{Surgical prevention}

\section{Bariatric surgery}

A meta-analysis of three cohort studies found a $60 \%$ reduction in risk of EC after bariatric surgery compared to obese controls who did not have surgery $(\mathrm{RR}=0.4,95 \% \mathrm{CI} 0.2-$ $0.79) .{ }^{24}$ This risk reduction may be as high as $81 \%$ in women who are able to achieve and maintain a normal weight after surgery. ${ }^{42}$ Additionally, the prevalence of asymptomatic endometrial hyperplasia in obese women presenting for bariatric surgery ranges from $7 \%$ to $10 \% \cdot{ }^{43-45}$ In a small study of four patients with endometrial hyperplasia at the time of bariatric surgery, three had complete resolution 2 years later, likely due to weight loss (average loss $41 \mathrm{~kg}$ ). ${ }^{46}$

\section{Chemoprevention}

\section{Oral contraceptives pills}

Progestin-containing contraceptives, such as OCPs, have antiestrogenic effects on the endometrium and decrease EC risk. A meta-analysis of 36 case-control studies showed a $31 \%$ risk reduction in women who had ever used OCPs compared to never users ( $\mathrm{RR}=0.69,99 \% \mathrm{CI} 0.66-0.73) .{ }^{47}$ Longer use of OCP resulted in lower EC incidence, and the effects persisted for at least 30 years after cessation of use. Despite reductions in OCPs' estrogen content since the 1960s, the risk reduction was the same, suggesting that the progesterone effect was similar regardless of estrogen dose..$^{47}$

\section{Other contraceptive types}

One large case-control study found that injectable progestin (depot medroxyprogesterone acetate) is similarly protective against EC, with effects lasting up to 8 years $(\mathrm{RR}=0.21$, 95\% CI 0.06-0.79).$^{48}$ For levonorgestrel intrauterine devices (IUDs), a pooled analysis of four cohort and 14 case-control studies found a $31 \%$ reduction in odds of EC, with stronger effects with longer use (odds ratio $[\mathrm{OR}]=0.69,95 \% \mathrm{CI}$ $0.58-0.82) .{ }^{49}$

\section{Hormone replacement therapy}

There is strong evidence that estrogen-only HRT increases the risk of EC in women with an intact uterus. ${ }^{50}$ However, when combined therapy is used, the addition of continuous progestin mitigates EC risk. ${ }^{50}$ Both the Women's Health Initiative $\mathrm{RCT}^{51}$ and the Million Women Study, a UK cohort study, demonstrated that combined continuous HRT does 
Table 2 Summary of recent meta-analyses on endometrial cancer prevention

\begin{tabular}{|c|c|c|c|}
\hline & Direction of risk & Relative risk $(95 \% \mathrm{CI})$ & Studies included \\
\hline \multicolumn{4}{|l|}{ Lifestyle prevention } \\
\hline Obesity $(\mathrm{BMI}>30)^{20}$ & $\uparrow$ & $2.54(2.11-3.06)^{*}$ & 7 cohort, II case-control \\
\hline Physical activity ${ }^{27}$ & $\downarrow$ & $0.77(0.70-0.85)^{*}$ & 7 cohort \\
\hline Dairy intake ${ }^{36}$ & No effect & $0.97(0.93-1.01)^{\mathrm{a}}$ & I cohort, 8 case-control \\
\hline Coffee intake ${ }^{37}$ & $\downarrow$ & $0.8(0.74-0.86)^{*}$ & 13 cohort \\
\hline \multirow[t]{2}{*}{ Tea intake $e^{38}$} & No effect & Green tea: $0.78(0.66-0.92)^{*}$ & Green tea: I cohort, 5 case-control \\
\hline & & Black tea: 0.99 (0.79-I.23) & Black tea: 5 cohort, 4 case-control \\
\hline Red meat intake ${ }^{36}$ & $\uparrow$ & $1.51(1.19-1.93)^{*}$ & 7 case-control \\
\hline \multirow[t]{2}{*}{ Alcohol intake ${ }^{39}$} & No effect & 0.83 (0.59-I.18) (cohort analysis) & 6 cohort, 14 case-control \\
\hline & & 0.89 (0.76-I.05) (case-control analysis) & \\
\hline \multirow[t]{2}{*}{ Smoking ${ }^{41}$} & $\downarrow$ & $0.8 \mathrm{I}(0.74-0.88)^{*}$ (cohort analysis) & 10 cohort, 24 case-control \\
\hline & & $0.72(0.66-0.79) *$ (case-control analysis) & \\
\hline Breastfeeding ${ }^{60}$ & $\downarrow$ & $0.77(0.62-0.96)$ & 14 cohort \\
\hline \multicolumn{4}{|l|}{ Surgical prevention } \\
\hline Bariatric surgery ${ }^{24}$ & $\downarrow$ & $0.4(0.2-0.79)^{*}$ & 3 cohort \\
\hline \multicolumn{4}{|l|}{ Chemoprevention } \\
\hline Oral contraceptive pills ${ }^{47}$ & $\downarrow$ & $0.69(0.66-0.73)^{\mathrm{b}, *}$ & I5 cohort, 2 I case-control \\
\hline Levonorgestrel intrauterine device ${ }^{49}$ & $\downarrow$ & $0.69(0.58-0.82)^{c, *}$ & 4 cohort, I4 case-control \\
\hline Estrogen-only HRT $T^{50}$ & $\uparrow$ & $2.3(2.1-2.5)^{*}$ & 10 cohort, 27 case-control \\
\hline Combined estrogen-progesterone $\mathrm{HRT}^{50}$ & $\downarrow$ & $0.4(0.2-0.6)^{*}$ & I RCT, 3 cohort, 3 case-control \\
\hline \multirow[t]{3}{*}{ Nonsteroidal anti-inflammatory drugs ${ }^{53}$} & $\downarrow$ & Overall: $0.87(0.79-0.96)^{*}$ & 4 cohort, 5 case-control \\
\hline & & Obese: $0.72(0.58-0.90)^{*}$ & \\
\hline & & Nonobese: 1.08 (0.82-1.43) & \\
\hline
\end{tabular}

Notes: *Significant at $P<0.05$. 'Odds ratio shown, per serving of dairy per day. ${ }^{\circ} 99 \% \mathrm{Cl}$ given. ${ }^{\mathrm{c}}$ Odds ratio shown.

Abbreviations: $\mathrm{Cl}$, confidence interval; BMI, body mass index; RCT, randomized controlled trial; HRT, hormone replacement therapy.

not increase EC risk. In fact, in the Million Women Study, it actually lowered the risk ( $\mathrm{RR}=0.71,95 \%$ CI $0.56-0.90)$, whereas regimens with cyclic progesterone or unopposed estrogen increased EC risk. ${ }^{52}$

\section{Other chemopreventive strategies}

Nonsteroidal anti-inflammatory drugs (NSAIDs) may decrease EC risk. A meta-analysis of nine case-control studies found a reduction in risk in obese women only $(\mathrm{RR}=0.72$, 95\% CI 0.58-0.90). ${ }^{53}$ These data are encouraging, but there is a lack of randomized or prospective data to support NSAID use to reduce EC risk.

Metformin has antiproliferative effects on hyperplastic and cancerous endometrium in vitro. ${ }^{54,55}$ However, the three large cohort studies are conflicting and inconclusive on the clinical benefits of metformin for EC prevention. ${ }^{56-58}$ One trial is currently recruiting obese postmenopausal women at high risk for EC to see whether metformin in combination with lifestyle changes could decrease EC occurrence. ${ }^{59}$

\section{Breastfeeding}

A recent meta-analysis found that breastfeeding reduces the risk of EC by $33 \%$ (RR $0.77,95 \%$ CI $0.62-0.96$ ). They also demonstrated a dose-response relationship: for each 1 month of breastfeeding duration, risk of $\mathrm{EC}$ was reduced by $2 \%$ (RR 0.98, 95\% CI 0.97-0.99). ${ }^{60}$

\section{Summary and recommendations}

Women at risk for EC should be counseled on the benefits of increasing physical activity, even light or moderate activity, as well as the benefits of weight loss for EC risk reduction. Morbidly obese women (BMI $\geq 40 \mathrm{~kg} / \mathrm{m}^{2}$ ) should be counseled about the health benefits of bariatric surgery, including the impressive EC risk reduction. While no particular diet appears to reduce EC risk, sugar-sweetened beverages and diets with high glycemic load should be avoided. Women should also be counseled about the benefits of EC risk reduction with progestin-containing contraceptives. Table 2 summarizes the findings of included meta-analyses.

\section{Opportunities for improved management and survivorship in EC Background}

There are an estimated 610,000 women with a history of EC in US alone. ${ }^{61}$ Most EC patients present early with symptoms, so the majority are cured surgically with or without adjuvant therapy. The RR of mortality is 6.25 times higher in morbidly obese survivors compared to normal-weight survivors. ${ }^{8}$ 
In fact, EC survivors are more likely to die of cardiovascular disease than cancer. ${ }^{7}$ As such, addressing risk factors for cardiovascular disease at the time of EC diagnosis could have the greatest impact on survival. ${ }^{7}$

\section{Obesity and physical activity}

A Cochrane analysis of 56 RCTs of exercise during cancer treatment, including EC treatment, demonstrated a significant improvement in health-related QoL with exercise ranging from yoga to strength training. ${ }^{62}$ Obese EC survivors stand to gain from positive effects of exercise, as surveys indicate that they have lower QoL than normal-weight survivors. ${ }^{63}$ Nonetheless, most EC survivors are not able to meet the physical activity guidelines. Only $1 \%$ of earlystage EC survivors are able to meet all the ACS guidelines (Table 1 ), and only $12 \%$ are able to meet the physical activity guidelines, which has been associated with worse QoL and fatigue. ${ }^{64}$

EC survivors frequently report wanting to eat better, be healthier, and lose weight. ${ }^{65,66}$ Yet only $50 \%$ of women with history of endometrial hyperplasia or cancer survivors are aware that obesity contributed to their cancer risk. ${ }^{67}$ Gynecologic oncologists are not trained to discuss obesity management, ${ }^{68}$ and only $10 \%$ members of the Society for Gynecologic Oncology reported having any training in weight loss counseling; however, those formally trained were more comfortable discussing weight loss with patients. ${ }^{68}$ EC survivors report finding weight loss counseling motivating and denied that it undermined the physician-patient relationship, preferring that their oncologist give specific recommendations for lifestyle improvement. ${ }^{69}$

Several recent studies conducted lifestyle interventions as shown in Table $3 .^{70-73}$ The survivors of uterine cancer empowered by exercise and healthy diet (SUCCEED) RCT showed significant weight loss, increased physical activity, greater fruit and vegetable consumption, and improved QoL in EC survivors after an intensive 6-month group and individual lifestyle intervention. ${ }^{70,71}$ The Steps to Health study found similar results with a home-based exercise intervention with significant improvement in physical activity, heart rate, and systolic blood pressure in obese and nonobese participants. ${ }^{73}$ Low-cost intervention with a mobile health application Loseit! also showed short-term weight loss in EC survivors. The revving-up exercise for sustained weight loss by altering neurological reward and drive (REWARD) RCT is currently recruiting obese EC survivors to study different types of exercise and weight loss. ${ }^{74}$

However, not all exercise studies have been successful: Rossi et $\mathrm{al}^{66}$ recruited ethnically diverse, low-income women with a history of EC. While $86 \%$ of the women surveyed expressed some interest in joining a free exercise program, only $5 \%$ came to the scheduled exercise classes. The authors emphasize the fact that care needs to be taken to determine barriers to exercise in vulnerable low-income and/or minority populations.

\section{Diet}

Few studies differentiate the effect of diet alone and its effect on EC survivorship. EC survivors who report meeting the ACS recommendations for diet, physical activity, and abstaining from smoking have higher QoL. ${ }^{75}$ In the absence of EC-specific dietary interventional trials, EC survivors should be counseled on the ACS recommendations for healthy eating, given their other benefits.

\section{Medications}

Metformin has been evaluated in EC survivors with conflicting results. Although a large retrospective cohort study reported that women with diabetes on metformin at the time of EC diagnosis had improved recurrence-free survival and overall survival, two subsequent cohort studies failed to replicate this benefit. ${ }^{76-78}$ A recent retrospective cohort study suggested that there may be lower recurrence rates in metformin users, but only in those with type 1 EC. ${ }^{79}$ Given the need for prospective data, there are multiple metformin trials ongoing, including one evaluating the addition of metformin to standard platinum-based chemotherapy for patients with advanced stage or recurrent EC. ${ }^{80}$

\section{Summary and recommendations}

EC survivors are frequently overweight and inactive. Several RCTs have demonstrated that physical activity and dietary counseling interventions improve weight loss and QoL, although the studies were small and heterogeneous. All providers caring for EC survivors, especially gynecologic oncologists, need more and better training to discuss lifestyle interventions at the time of diagnosis. While diet does not appear to affect EC survivorship, metformin shows promise as an agent to reduce recurrence risk.

\section{Opportunities for prevention of OC Background}

In 2015, there were an estimated 21,000 cases of OC and over 14,000 deaths in the US. ${ }^{14}$ The incidence of epithelial ovarian cancer (EOC), which makes up over $90 \%$ of OC, is predicted to increase as the world's population ages. ${ }^{9}$ As EOC remains the deadliest gynecologic cancer, much of the recent research focuses on prevention. 


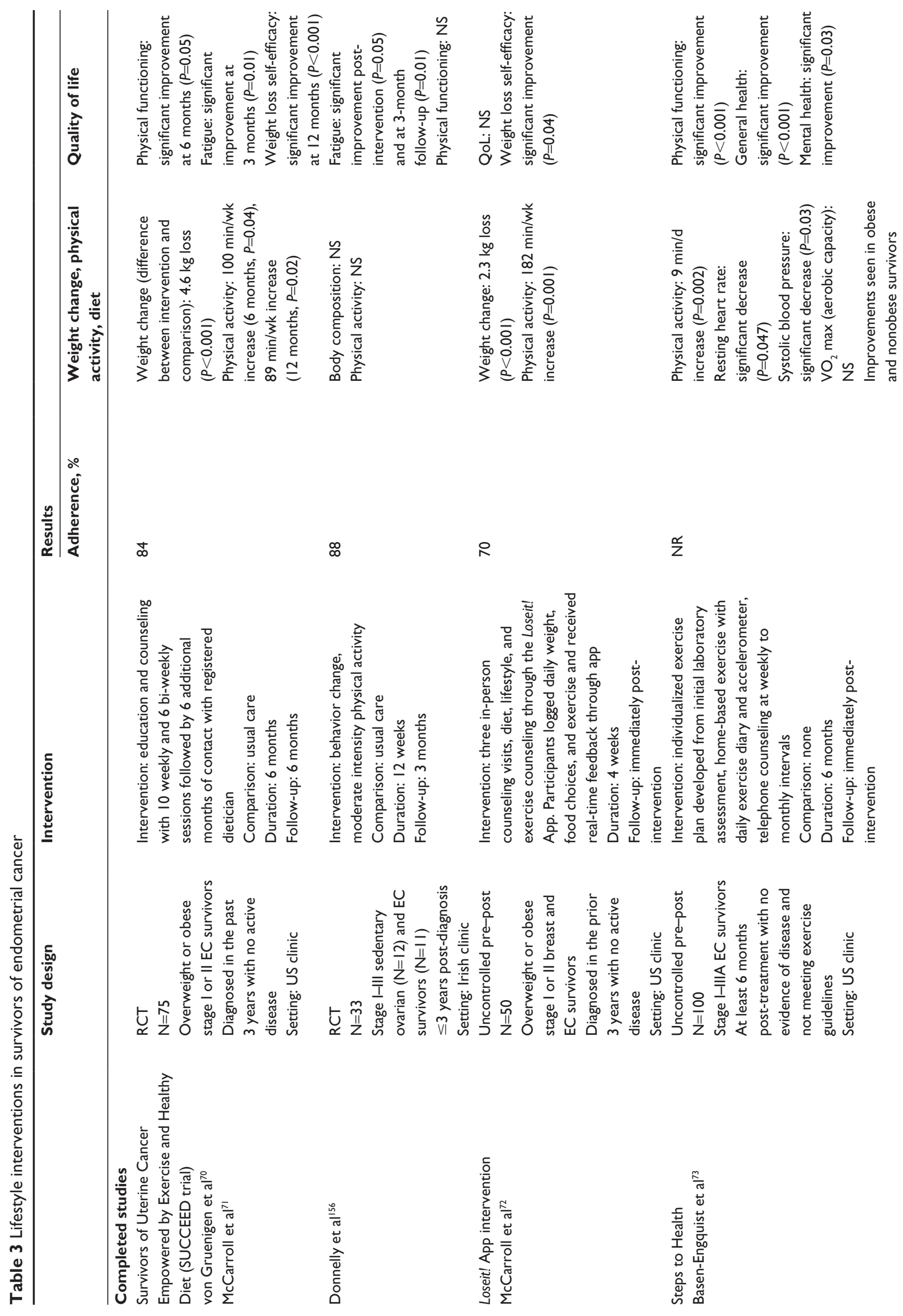




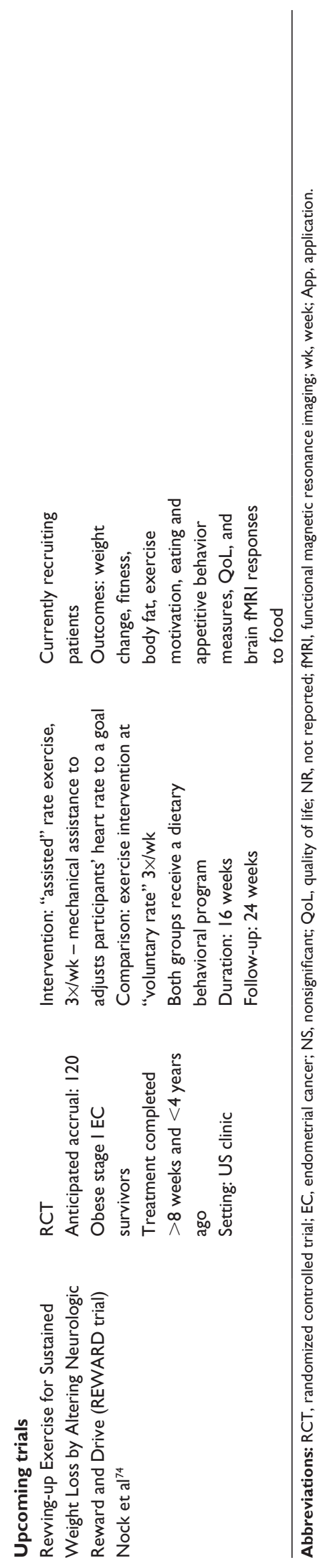

\section{Lifestyle prevention Weight loss and physical activity}

Obesity may be a risk factor for OC, although its effect is much less than for EC. While the Women's Health Initiative cohort and Nurses' Health Study found no association, a meta-analysis of 47 studies reported a $12 \%$ increased risk of EOC for obese women (BMI $\left.>30 \mathrm{~kg} / \mathrm{m}^{2}\right)(99 \%$ CI 1.05-1.19, adjusted for age, parity, hysterectomy, menopausal status, OCP usage, HRT usage, and height). ${ }^{81-83}$ Physical activity appears to offer a modest preventive benefit: a review of 26 studies found mixed effect in cohort studies but a significant risk reduction among the most active women in case-control studies ${ }^{84}$ A meta-analysis of nine cohort and ten case-control studies reported an $8 \%$ nonsignificant risk reduction $(95 \% \mathrm{CI}$ 0.84-1.00) for any physical activity versus no physical activity and a nonsignificant $11 \%$ risk reduction $(95 \%$ CI $0.79-1.01)$ for high levels of physical activity versus none. ${ }^{85}$ The majority of physical activity studies included in these meta-analyses were controlled for age, BMI, and family history of OC.

Diet

The sole diet RCT, the Women's Health Initiative trial, found reduction in EOC risk with a low-fat diet with a hazard ratio (HR) of 0.60 (95\% CI 0.38-0.96) at 8 years post-intervention but not at 4 years post-intervention, suggesting that long-term adherence to a low-fat diet was needed for benefit. ${ }^{31}$ Cohort studies, including the Nurses' Health Study, have found no significant association between fat intake and EOC incidence. 86,87 $^{86}$ The Nurses' Health Study also found no association with two healthy eating indices or a Mediterranean diet. 88,89

Vegetable intake may have a small impact on EOC risk: two meta-analyses of cohort and case-control studies reported $11 \%-16 \%$ risk reduction with daily vegetable consumption (95\% CI $0.81-0.99$ and $0.75-0.94$, respectively) ${ }^{90,91}$ Metaanalyses have found no significant association with dairy, ${ }^{92}$ fish, ${ }^{93}$ fiber, or dietary and antioxidant nutrients. ${ }^{87}$

\section{Coffee, tea, alcohol, and other beverages}

Coffee and tea are thought to have antioxidant and antiinflammatory properties, although the benefit is unproven in EOC. A meta-analysis of seven cohort and case-control studies, including the Nurses' Health Study, found no association between coffee and EOC incidence. ${ }^{94}$ One casecontrol study published later reported a modest decrease in odds with increasing coffee consumption (OR $=0.90,95 \%$ CI $0.84-0.97 \mathrm{per}$ cup/d) and total caffeine consumption (OR $=0.93,95 \%$ CI $0.88-0.98$ per $100 \mathrm{mg} / \mathrm{d}$ ), significant only for serous tumors. ${ }^{95}$ 
For tea, a systematic review of 16 studies and a metaanalysis of six case-control studies found no association..$^{94,96}$ The Nurses' Health Study has since reported decreased odds with one or more cups of black tea per day $(\mathrm{OR}=0.68,95 \%$ CI $0.51-0.90) .{ }^{97}$ For green tea, a meta-analysis of six casecontrol studies reported decreased odds with consumption of one or more cups per day ( $\mathrm{OR}=0.81,95 \%$ CI $0.73-0.89) .{ }^{98}$

Sugar-sweetened beverages appear to have little to no effect on EOC incidence in two cohort and one case-control studies. ${ }^{99-101}$

While alcohol increases the risk of breast and other cancers, there appears to be no association with EOC. Three meta-analyses of cohort and case-control studies found no overall association with heavy, moderate, or low levels of drinking overall with a possible protective effect on endometrioid EOC only ( $\mathrm{RR}=0.82,95 \%$ CI $0.70-0.96) .{ }^{102-104}$

\section{Smoking}

While most types of EOC are not associated with smoking, a meta-analysis of 51 studies found an increased risk of mucinous EOC ( $R R=1.79,95 \%$ CI 1.60-2.00), with a dose-response relationship for pack-years of smoking. ${ }^{105-107}$ Smoking cessation should be recommended for all women.

\section{Breastfeeding}

A meta-analysis of five cohort and 35 case-control studies reported a $24 \%$ reduction in EOC risk (95\% CI 0.69-0.83), and longer duration of breastfeeding was associated with decreased odds of EOC. ${ }^{108,109}$

\section{Surgical prevention}

\section{Tubal ligation and salpingectomy}

It is now believed that the majority of EOCs arise from abnormalities in the fallopian tube. Tubal ligation decreased the risk of EOC by up to $30 \%$ in the most recent metaanalysis of seven cohort and 23 case-control studies (95\% CI 0.641-0.75). ${ }^{110}$ The Society for Gynecologic Oncology recommends salpingectomy after childbearing is complete during elective pelvic surgeries, hysterectomy, or as an alternative to tubal ligation. ${ }^{111}$ Bilateral salpingo-oophorectomy for those at high genetic risk (eg, BRCA1 and two mutation carriers) is recommended at age 35 or upon the completion of childbearing and decreases their risk of OC by $80 \% .{ }^{112}$

\section{Chemoprevention}

\section{Oral contraceptive pills}

A meta-analysis of 13 cohort and 32 case-control studies found a $27 \%$ risk reduction in EOC in ever versus never users
(95\% CI 0.70-0.76) with a dose-response relationship and persistent benefits up to 30 years after use. Similar risk reductions were seen for epithelial and nonepithelial tumors, but OCPs appeared to have little effect on mucinous tumors. ${ }^{113}$ Low-dose estrogen OCPs, the most commonly used at present, may provide the greatest risk reduction. ${ }^{114}$

\section{Other contraception types}

There is no conclusive evidence that non-OCP contraception prevents EOC. For injectable progestin contraception, two case-control studies found reductions in odds of EOC of $39 \%$ (95\% CI $0.44-0.85)$ for any use and $93 \%$ for 5 years of use (95\% CI 0.01-0.49), ${ }^{15,116}$ while prior case-control ${ }^{117}$ and cohort ${ }^{118}$ studies found no significant association. For IUDs, no association was found in one cohort study and two case-control studies. These studies were conducted in the People's Republic of China where nonhormonal IUDs (steel ring) are the most common. ${ }^{119-121}$

\section{Hormone replacement therapy}

The 2002 Women's Health Initiative trial showed an increased risk of cardiovascular disease, breast cancer, and possibly EOC with HRT. ${ }^{122,123}$ A meta-analysis of 17 cohort and 38 case-control studies found a $37 \%$ increased risk of EOC (95\% CI 1.27-1.48) for ever users of HRT compared to never users, consistent with the possible risk increase in the Women's Health Initiative RCT. ${ }^{124}$ There were similar risks with estrogen-only and estrogen-progesterone formulations, and risk was significantly increased with serous and endometrioid cancers. While risks decreased in ex-HRT users, the increased risk persisted for 5 years after stopping HRT. ${ }^{125}$ However, the absolute risk is low with an estimated increase of one extra case among 1,000 HRT users and one extra death from EOC among 1,700 HRT users.

\section{Other chemopreventive strategies}

Both statins and NSAIDs have been proposed for chemoprevention, given their anti-inflammatory properties. For statins, one case-control study found no association with EOC risk, but research is ongoing. ${ }^{126,127}$ For NSAIDs, no association or dose-response relationship was seen in the one RCT or the Nurses' Health Study cohort, and four recent meta-analyses suggest limited to no benefit. ${ }^{128-133}$ However, aspirin specifically is associated with a modest reduction in risk (OR 0.91, 95\% CI 0.84-0.99) and research is ongoing. ${ }^{130}$ NSAIDs are not currently recommended for EOC prevention in the absence of another indication for use. 
Table 4 Summary of recent meta-analyses on ovarian cancer prevention

\begin{tabular}{|c|c|c|c|}
\hline & Direction of risk & Relative risk $(95 \% \mathrm{Cl})$ & Studies included \\
\hline \multicolumn{4}{|l|}{ Lifestyle prevention } \\
\hline Obesity $(\mathrm{BMI}>30)^{81}$ & $\uparrow$ & $1.13(1.06-1.20)^{\mathrm{a}, *}$ & I cohort, 30 case-control \\
\hline Physical activity ${ }^{84}$ & No effect & $0.92(0.84-1.00)$ & 9 cohort, 10 case-control \\
\hline Vegetable intake ${ }^{89,90}$ & $\downarrow$ & $0.89(0.81-0.99)^{*}$ & 4 cohort, 4 case-control \\
\hline Dairy intake ${ }^{91}$ & No effect & $0.925(0.78-1.09)^{\mathrm{b}}$ & 19 case-control \\
\hline \multirow[t]{2}{*}{ Fish intake ${ }^{92}$} & No effect & $1.04(0.89-1.22)$ (cohort analysis) & 5 cohort, 10 case-control \\
\hline & & $0.90(0.73-1.12)$ (case-control analysis) & \\
\hline Coffee intake ${ }^{93}$ & No effect & $1.05(0.75-1.46)$ & 7 case-control \\
\hline Tea intake ${ }^{93,95}$ & No effect & $1.07(0.78-1.45)$ & 6 case-control \\
\hline Alcohol intake $e^{101}$ & No effect & $1.03(0.96-1.10)$ & 13 cohort \\
\hline Smoking 105 & $\uparrow$ & $1.07(1.03-1.10)^{\mathrm{a}, *}$ & 19 cohort, 21 case-control \\
\hline Breastfeeding ${ }^{107}$ & $\downarrow$ & $0.76(0.69-0.83)^{*}$ & 5 cohort, 35 case-control \\
\hline \multicolumn{4}{|l|}{ Surgical prevention } \\
\hline Tubal ligation ${ }^{109}$ & $\downarrow$ & $0.7(0.64-0.75)^{*}$ & 7 cohort, 23 case-control \\
\hline \multicolumn{4}{|l|}{ Chemoprevention } \\
\hline Oral contraceptive pills ${ }^{112}$ & $\downarrow$ & $0.73(0.70-0.76)^{*}$ & I 3 cohort, 32 case-control \\
\hline Hormone replacement therapy & $\uparrow$ & $1.14(1.10-1.19)^{*}$ & I7 cohort, 35 case-control \\
\hline \multicolumn{4}{|l|}{ (estrogen only and combined) ${ }^{123}$} \\
\hline \multirow[t]{3}{*}{ Nonsteroidal anti-inflammatory drugs ${ }^{129}$} & No effect & Aspirin: 0.91 (0.84-0.99) & I 2 case-control \\
\hline & & NSAIDs: $0.90(0.77-1.05)$ & \\
\hline & & Acetaminophen: 0.99 (0.88-I.12) & \\
\hline
\end{tabular}

Notes: *Significant at $P<0.05$. ${ }^{999 \%} \mathrm{Cl}$ given. ${ }^{b}$ Odds ratio shown is for 13 studies of low-fat/skimmed milk as dairy studies were analyzed by main type of dairy. Abbreviations: $\mathrm{Cl}$, confidence interval; BMI, body mass index; NSAID, nonsteroidal anti-inflammatory drug.

Similar to EC, metformin is thought to inhibit cellular pathways involved in some EOCs. One cohort ${ }^{56}$ and one case-control study ${ }^{134}$ found a nonsignificant trend toward reduced risk of EOC with use, while two other cohorts found no association between EOC and metformin use..$^{58,135}$

Table 4 summarizes findings of included metaanalyses.

\section{Summary and recommendations}

While physical activity and diet do not majorly affect EOC risk, women should be counseled on the benefits of maintaining a healthy weight and active lifestyle for overall health. Obese women should be counseled on the modest increased risk of EOC, and smoking should be strongly discouraged. Women considering different contraceptive options should be counseled on preventive benefits of OCPs and tubal ligation or salpingectomy for EOC risk reduction.

\section{Opportunities for improved management and survivorship in OC Background}

OC continues to have a high mortality rate with median survival of $40 \%-50 \%$ at 10 years. Many patients who initially respond to chemotherapy and surgery have EOC recurrence, which is often incurable. ${ }^{9}$ In this context, QoL is important, and lifestyle interventions may play a role in optimizing survivors' experiences.

\section{Obesity and physical activity}

Obesity may affect survival and QoL after EOC diagnosis. A meta-analysis of 21 case-control studies reported increased mortality risk of 1.12 (95\% CI 1.01-1.25) for women with BMI $\geq 35.0 \mathrm{~kg} / \mathrm{m}^{2}$ as well as negative effects of obesity on progression-free survival and EOC-specific survival. ${ }^{136}$ In contrast, the Women's Health Initiative cohort found no association of BMI and mortality after EOC diagnosis. ${ }^{83}$ QoL may be lower in obese survivors, but further research is needed. ${ }^{137}$

Surveys suggest that most EOC survivors are inactive, with only $19 \%$ meeting ACS guidelines. ${ }^{138,139}$ Yet similar to EC, in two cross-sectional studies, exercise has been associated with improved QoL and mental health and reduced fatigue in EOC survivors. ${ }^{140,141}$ The Women's Health Initiative cohort study reported that vigorous physical activity prior to diagnosis was associated with a $24 \%$ lower risk of overall mortality (95\% CI $0.58-0.98)$ compared with no vigorous physical activity ${ }^{83}$ However, fatigue may be one of the biggest barriers to exercise during or post-treatment, especially in women without established exercise routines. ${ }^{139,142}$

Table 5 presents the five small studies examining the impact of exercise interventions on EOC survivors. ${ }^{140,143-146}$ 


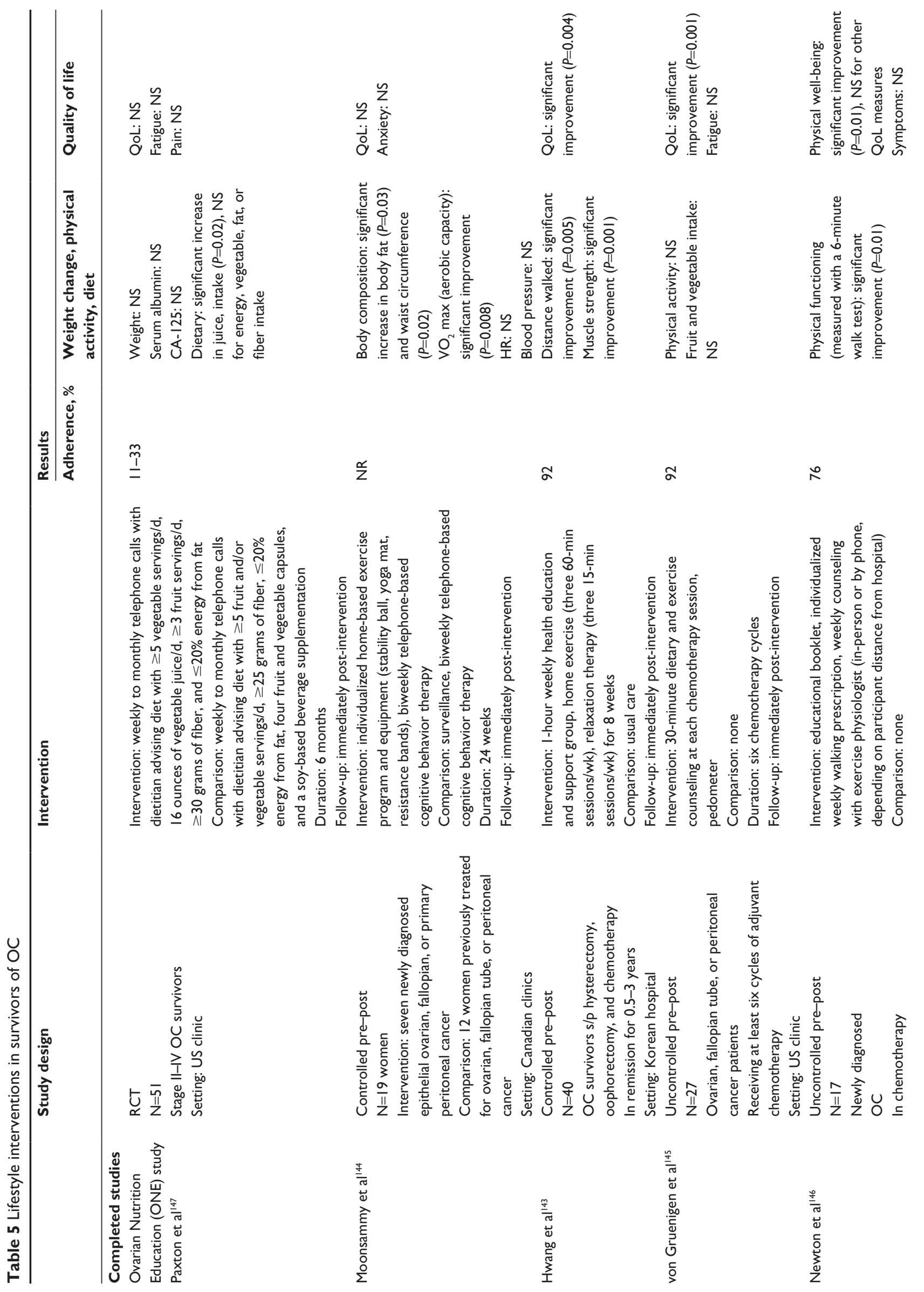



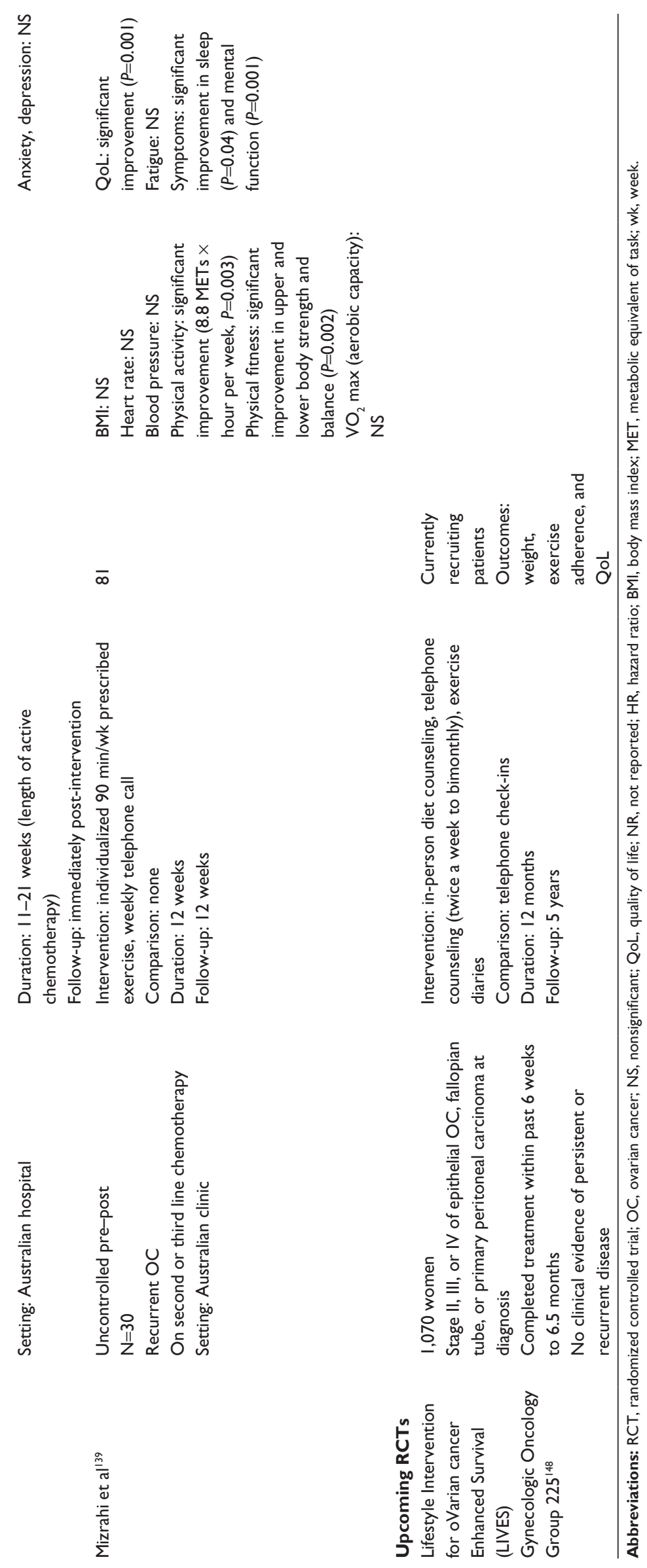
Four studies reported increased physical activity at the end of counseling. Of the two studies on weight change, one reported no significant change and one reported weight gain. ${ }^{144,147}$ Three of five studies on QoL reported improvement. ${ }^{140,144-146}$ As exercise has significant, noncancer benefits, exercise counseling or other methods to support physical activity should be incorporated into EOC survivorship management.

\section{Diet}

Dietary intervention in EOC survivors is an active area of ongoing research. The Women's Health Initiative cohort found higher quality diet to be associated with lower all-cause mortality, independent of physical activity ( $\mathrm{HR}=0.73,95 \%$ CI 0.55-0.97). ${ }^{148}$ As shown in Table 5, one of two interventions showed slight improvements in diet with in-person counseling, and there is one ongoing trial of dietary counseling and exercise in EOC survivors. ${ }^{145,147,149}$

\section{Medications}

Statins have been proposed for prevention of EOC recurrence, and one case-control study found decreased mortality (age-adjusted HR $=0.47,95 \%$ CI $0.26-0.85$ ), although further research is needed. ${ }^{126}$ Given the link between HRT and EOC incidence, its use in survivors has been recently studied. One meta-analysis of two RCTs and four cohort studies found no increased risk of recurrence with postoperative HRT use. ${ }^{150}$ A recent RCT actually reported improved overall and relapse-free survival in women using HRT after surgical or chemotherapy treatment $(\mathrm{HR}=0.63$, 95\% CI $0.44-0.90$ and HR $=0.67,95 \%$ CI $0.47-0.97$, respectively). ${ }^{151}$

\section{Summary and recommendations}

Similar to EC, EOC survivors are frequently inactive, and obesity may adversely impact survival and QoL. Small intervention studies show that exercise improves QoL, but the long-term effects on weight and mortality are unknown. Diet does not affect EOC survivorship. HRT appears to be safe in EOC survivors.

\section{Discussion}

The obesity epidemic is driving an alarming increase in lifestyle-related cancers in the US and worldwide. ${ }^{2,5}$ As this review shows, modifiable lifestyle factors substantially impact the incidence of EC and OC and the health of cancer survivors. There are multiple areas in which interventions could prevent cancer and improve survivors' QoL.
Obesity increases the risk of EC, increases the risk of OC to a lesser extent, and adversely impacts the health of survivors. Bariatric surgery offers a unique opportunity to prevent EC and reduce other obesity-related morbidities that are the main cause of death for EC survivors. Modeling analyses suggest that bariatric surgery could be cost-effective as part of early-stage EC treatment and would decrease mortality in these patients. ${ }^{152}$ Less drastic interventions, such as physician counseling and exercise programs, may also impact EC survival, given promising effects on weight loss from the current small trials, but these interventions are underutilized. Training all women's health providers, including gynecologic oncologists and generalist gynecologists, in obesity counseling is critical to help more women understand and begin to address lifestyle-related cancer risk. However, counseling should be combined with additional interventions to effect meaningful change. A multidisciplinary, collective approach to obese, sedentary at-risk women and survivors of cancer, including collaborations with bariatric surgeons, physical activity counselors, and nutritionists, may help women lose weight and improve their long-term health. Longer term follow-up is also needed to determine whether weight loss impacts cancer recurrence and mortality in survivors. Although the magnitude of obesity's adverse effects is far less with OC, EOC incidence is estimated to increase $3 \%$ per decade with current obesity trends. ${ }^{82}$ Reducing obesity could reduce the burden of EC and OC as well as many other diseases.

Physical activity has only modest effects on EC prevention, but it improved health and QoL in EC and EOC survivors. For EC, exercise may also be a means to weight reduction, as seen in the few small, heterogeneous studies. For EOC, QoL improvements are particularly meaningful, given the limited life span of most survivors. Exercise should be integrated into gynecologic cancer survivorship care.

Diet and alcohol minimally impact the risk of EC and OC. Eating more vegetables and less red meat may be beneficial, and these recommendations are in line with general guidelines for healthy eating. Smoking increases mucinous EOC risk. Women's health providers should continue to encourage smoking cessation at every available opportunity.

New chemoprevention strategies are on the horizon, such as NSAIDs and metformin, with several current trials ongoing. Several other medications are being studied as well, such as beta-blockers for EOC survivors. ${ }^{153} \mathrm{HRT}$, on the other hand, is now firmly established to increase cancer risk for EOC and EC (except combined continuous HRT). 
In contrast, OCPs are estimated to have prevented 400,000 cases of EC and 200,000 cases of EOC, including 100,000 EOC deaths, in the past 50 years. ${ }^{47,113}$ Nonetheless, OCPs are underutilized for EOC prevention. In fact, $25 \%$ of women overall, and $40 \%$ of the high-risk women who would be the most likely to benefit, falsely believe that OCPs increase EOC risk. ${ }^{154,155}$ OCPs should continue to be included in the counseling of high-risk women as recommended by the Society for Gynecologic Oncology and ACS. ${ }^{111}$ Research on potential benefits of other hormonal contraceptives is needed, particularly as more women in developed countries transition to long-acting reversible contraception, such as injectable contraception and IUDs. Finally, as prophylactic tubal ligation and/or salpingectomy enters mainstream practice, continued research will be necessary to evaluate the impact on all-cause and EOC-specific mortality.

We found a paucity of intervention studies on modifiable lifestyle factors in EC and EOC survivors. While this reflects, in part, the newness of these discoveries, even well-established interventions have not been scaled out to reach all those who might benefit. We eagerly anticipate the results of ongoing lifestyle and chemoprevention trials and encourage more researchers to pursue this area from which so many women may benefit.

\section{Conclusion}

Lifestyle factors, such as overweight/obesity and sedentary living, increase the risk of developing EC and OC. As low- and middle-income countries undergo transition to a Western sedentary lifestyle and are further burdened by obesity, addressing modifiable risk factors will be even more important to minimize the gynecologic cancer burden and optimize survivorship globally.

\section{Disclosure}

The authors report no conflicts of interest in this work.

\section{References}

1. Stevens G. Global health risks: mortality and burden of disease attributable to selected major risks. Bull World Health Organ. 2009;87: 646-646.

2. Carter BD, Abnet CC, Feskanich D, et al. Smoking and mortality - beyond established causes. N Engl J Med. 2015;372(7): 631-640.

3. Colditz GA, Atwood KA, Emmons K, et al. Harvard report on cancer prevention volume 4: Harvard cancer risk index. Cancer Causes Control. 2000;11(6):477-488.

4. De Pergola G, Silvestris F. Obesity as a major risk factor for cancer. J Obes. 2013;2013:291546.

5. Ryan AM, Cushen S, Schellekens H, et al. Poor awareness of risk factors for cancer in Irish adults: results of a large survey and review of the literature. Oncologist. 2015;20(4):372-378.
6. Kelly T, Yang W, Chen C-S, Reynolds K, He J. Global burden of obesity in 2005 and projections to 2030. Int JObes (Lond). 2008;32(9): 1431-1437.

7. Ward KK, Shah NR, Saenz CC, McHale MT, Alvarez EA, Plaxe SC. Cardiovascular disease is the leading cause of death among endometrial cancer patients. Gynecol Oncol. 2012;126(2):176-179.

8. Calle EE, Rodriguez C, Walker-Thurmond K, Thun MJ. Overweight, obesity, and mortality from cancer in a prospectively studied cohort of U.S. adults. N Engl J Med. 2003;348(17):1625-1638.

9. Jayson GC, Kohn EC, Kitchener HC, Ledermann JA. Ovarian cancer. Lancet. 2014;384(9951):1376-1388.

10. Toledo E, Salas-Salvadó J, Donat-Vargas C, et al. Mediterranean diet and invasive breast cancer risk among women at high cardiovascular risk in the PREDIMED Trial. JAMA Intern Med. 2015;175(11):1752-1760.

11. Sutcliffe P, Connock M, Gurung T, et al. Aspirin for prophylactic use in the primary prevention of cardiovascular disease and cancer: a systematic review and overview of reviews. Health Technol Assess. 2013; 17(43):1-253.

12. Kushi LH, Doyle C, McCullough M, et al. American Cancer Society Guidelines on nutrition and physical activity for cancer prevention: reducing the risk of cancer with healthy food choices and physical activity. CA Cancer J Clin. 2012;62(1):30-67.

13. Rock CL, Doyle C, Demark-Wahnefried W, et al. Nutrition and physical activity guidelines for cancer survivors. CA Cancer J Clin. 2012;62(4):243-274.

14. Siegel RL, Miller KD, Jemal A. Cancer statistics, 2015. CA Cancer J Clin. 2015;65(1):5-29.

15. Torre LA, Bray F, Siegel RL, Ferlay J, Lortet-Tieulent J, Jemal A. Global cancer statistics, 2012. CA Cancer J Clin. 2015;65(2):87-108.

16. Schmandt RE, Iglesias DA, Co NN, Lu KH. Understanding obesity and endometrial cancer risk: opportunities for prevention. Am J Obstet Gynecol. 2011;205(6):518-525.

17. Talavera F, Reynolds RK, Roberts JA, Menon KM. Insulin-like growth factor I receptors in normal and neoplastic human endometrium. Cancer Res. 1990;50(10):3019-3024.

18. Reeves GK, Pirie K, Beral V, Green J, Spencer E, Bull D. Cancer incidence and mortality in relation to body mass index in the Million Women Study: cohort study. BMJ. 2007;335(7630):1134.

19. Schouten LJ, Goldbohm RA, van den Brandt PA. Anthropometry, physical activity, and endometrial cancer risk: results from the Netherlands Cohort Study. J Natl Cancer Inst. 2004;96(21):1635-1638.

20. Zhang Y, Liu H, Yang S, Zhang J, Qian L, Chen X. Overweight, obesity and endometrial cancer risk: results from a systematic review and metaanalysis. Int J Biol Markers. 2014;29(1):e21-e29.

21. Setiawan VW, Yang HP, Pike MC, et al. Type I and II endometrial cancers: have they different risk factors? J Clin Oncol. 2013;31(20): 2607-2618.

22. Howlader N, Noone AM, Krapcho M, et al. [webpage on the Internet] SEER Cancer Statistics Review, 1975-2012, National Cancer Institute. Bethesda, MD; 2015 [updated November 18, 2015]. Available from: http://seer.cancer.gov/csr/1975_2012. Accessed January 6, 2016.

23. Parker ED, Folsom AR. Intentional weight loss and incidence of obesity-related cancers: the Iowa Women's Health Study. Int J Obes Relat Metab Disord. 2003;27(12):1447-1452.

24. Upala S, Anawin S. Bariatric surgery and risk of postoperative endometrial cancer: a systematic review and meta-analysis. Surg Obes Relat Dis. 2015;11(4):949-955.

25. Thompson HJ, McTiernan A. Weight cycling and cancer: weighing the evidence of intermittent caloric restriction and cancer risk. Cancer Prev Res (Phila). 2011;4(11):1736-1742.

26. Keum N, Greenwood DC, Lee DH, et al. Adult weight gain and adiposity-related cancers: a dose-response meta-analysis of prospective observational studies. J Natl Cancer Inst. 2015;107(2):dju428.

27. Voskuil DW, Monninkhof EM, Elias SG, Vlems FA, van Leeuwen FE; Task Force Physical Activity and Cancer. Physical activity and endometrial cancer risk, a systematic review of current evidence. Cancer Epidemiol Biomarkers Prev. 2007;16(4):639-648. 
28. Cust AE, Armstrong BK, Friedenreich CM, Slimani N, Bauman A. Physical activity and endometrial cancer risk: a review of the current evidence, biologic mechanisms and the quality of physical activity assessment methods. Cancer Causes Control. 2007;18(3):243-258.

29. Du M, Kraft P, Eliassen AH, Giovannucci E, Hankinson SE, De Vivo I. Physical activity and risk of endometrial adenocarcinoma in the Nurses' Health Study. Int J Cancer. 2014;134(11):2707-2716.

30. Patel AV, Feigelson HS, Talbot JT, et al. The role of body weight in the relationship between physical activity and endometrial cancer: results from a large cohort of US women. Int J Cancer. 2008;123(8): $1877-1882$.

31. Prentice RL, Thomson CA, Caan B, et al. Low-fat dietary pattern and cancer incidence in the women's health initiative dietary modification randomized controlled trial. J Natl Cancer Inst. 2007;99(20): 1534-1543.

32. Filomeno M, Bosetti C, Bidoli E, et al. Mediterranean diet and risk of endometrial cancer: a pooled analysis of three Italian case-control studies. Br J Cancer. 2015;112(11):1816-1821.

33. George SM, Ballard R, Shikany JM, Crane TE, Neuhouser ML. A prospective analysis of diet quality and endometrial cancer among 84,415 postmenopausal women in the Women's Health Initiative. Ann Epidemiol. 2015;25(10):788-793.

34. Mulholland HG, Murray LJ, Cardwell CR, Cantwell MM. Dietary glycaemic index, glycaemic load and endometrial and ovarian cancer risk: a systematic review and meta-analysis. Br J Cancer. 2008;99(3): 434-441.

35. Nagle CM, Olsen CM, Ibiebele TI, Spurdle AB, Webb PM. Glycemic index, glycemic load and endometrial cancer risk: results from the Australian National Endometrial Cancer study and an updated systematic review and meta-analysis. Eur J Nutr. 2013;52(2):705-715.

36. Bandera EV, Kushi LH, Moore DF, Gifkins DM, McCullough ML. Consumption of animal foods and endometrial cancer risk: a systematic literature review and meta-analysis. Cancer Causes Control. 2007;18(9): 967-988.

37. Zhou Q, Luo M-L, Li H, Li M, Zhou J-G. Coffee consumption and risk of endometrial cancer: a dose-response meta-analysis of prospective cohort studies. Sci Rep. 2015;5:13410.

38. Zhou Q, Li H, Zhou J-G, Ma Y, Wu T, Ma H. Green tea, black tea consumption and risk of endometrial cancer: a systematic review and meta-analysis. Arch Gynecol Obstet. 2015;293(1):143-155.

39. Sun Q, Xu L, Zhou B, Wang Y, Jing Y, Wang B. Alcohol consumption and the risk of endometrial cancer: a meta-analysis. Asia Pac J Clin Nutr. 2011;20(1):125-133.

40. Inoue-Choi M, Robien K, Mariani A, Cerhan JR, Anderson KE. Sugar-sweetened beverage intake and the risk of type I and type II endometrial cancer among postmenopausal women. Cancer Epidemiol Biomarkers Prev. 2013;22(12):2384-2394.

41. Zhou B, Yang L, Sun Q, et al. Cigarette smoking and the risk of endometrial cancer: a meta-analysis. Am J Med. 2008;121(6): 501.e-508.e.

42. Ward KK, Roncancio AM, Shah NR, et al. Bariatric surgery decreases the risk of uterine malignancy. Gynecol Oncol. 2014;133(1):63-66.

43. Modesitt SC, Hallowell PT, Slack-Davis JK, et al. Women at extreme risk for obesity-related carcinogenesis: baseline endometrial pathology and impact of bariatric surgery on weight, metabolic profiles and quality of life. Gynecol Oncol. 2015;138(2):238-245.

44. Kaiyrlykyzy A, Freese KE, Elishaev E, et al. Endometrial histology in severely obese bariatric surgery candidates: an exploratory analysis. Surg Obes Relat Dis. 2013;11(3):653-658.

45. Argenta P, Svendsen C, Elishaev E, et al. Hormone receptor expression patterns in the endometrium of asymptomatic morbidly obese women before and after bariatric surgery. Gynecol Oncol. 2014;133(1): $78-82$.

46. Linkov F, Elishaev E, Gloyeske N, et al. Bariatric surgery-induced weight loss changes immune markers in the endometrium of morbidly obese women. Surg Obes Relat Dis. 2014;10(5):921-926.
47. Collaborative Group on Epidemiological Studies on Endometrial Cancer. Endometrial cancer and oral contraceptives: an individual participant meta-analysis of 27,276 women with endometrial cancer from 36 epidemiological studies. Lancet Oncol. 2015;16(9): 1061-1070.

48. Depot-medroxyprogesterone acetate (DMPA) and risk of endometrial cancer. The WHO Collaborative Study of Neoplasia and Steroid Contraceptives. Int J Cancer. 1991;49(2):186-190.

49. Felix AS, Gaudet MM, La Vecchia C, et al. Intrauterine devices and endometrial cancerrisk: apooled analysis of the Epidemiology of Endometrial Cancer Consortium. Int J Cancer. 2015;136(5):E410-E422.

50. Grady D, Gebretsadik T, Kerlikowske K, Ernster V, Petitti D. Hormone replacement therapy and endometrial cancer risk: a meta-analysis. Obstet Gynecol. 1995;85(2):304-313.

51. Anderson GL, Judd HL, Kaunitz AM, et al. Effects of estrogen plus progestin on gynecologic cancers and associated diagnostic procedures: the Women's Health Initiative randomized trial. JAMA. 2003;290(13):1739-1748

52. Beral V, Bull D, Reeves G; Million Women Study Collaborators. Endometrial cancer and hormone-replacement therapy in the Million Women Study. Lancet (London, England). 2005;365(9470):1543-1551.

53. Neill AS, Nagle CM, Protani MM, Obermair A, Spurdle AB, Webb PM. Aspirin, nonsteroidal anti-inflammatory drugs, paracetamol and risk of endometrial cancer: a case-control study, systematic review and meta-analysis. Int J Cancer. 2013;132(5):1146-1155.

54. Tabrizi AD, Melli MS, Foroughi M, Ghojazadeh M, Bidadi S. Antiproliferative effect of metformin on the endometrium - a clinical trial. Asian Pac J Cancer Prev. 2014;15(23):10067-10070.

55. Tan BK, Adya R, Chen J, Lehnert H, Sant Cassia LJ, Randeva HS. Metformin treatment exerts antiinvasive and antimetastatic effects in human endometrial carcinoma cells. J Clin Endocrinol Metab. 2011; 96(3):808-816.

56. Tseng C-H. Metformin reduces ovarian cancer risk in Taiwanese women with type 2 diabetes mellitus. Diabetes Metab Res Rev. 2015; 31(6):619-626.

57. Ko EM, Stürmer T, Hong J-L, Castillo WC, Bae-Jump V, Funk MJ. Metformin and the risk of endometrial cancer: a population-based cohort study. Gynecol Oncol. 2015;136(2):341-347.

58. Soffer D, Shi J, Chung J, et al. Metformin and breast and gynecological cancer risk among women with diabetes. BMJ Open Diabetes Res care. 2015;3(1):e000049.

59. ClinicalTrials.gov [webpage on the Internet]. An Endometrial Cancer Chemoprevention Study of Metformin; 2012 [updated July 27, 2015]. Available from: https://linicaltrials.gov/ct2/show/NCT01697566? term= metformin+endometrial+cancer\&rank=4. Accessed December 30, 2015.

60. Wang L, Li J, Shi Z. Association between breastfeeding and endometrial cancer risk: evidence from a systematic review and meta-analysis. Nutrients. 2015;7(7):5697-5711.

61. Siegel R, DeSantis C, Virgo K, et al. Cancer treatment and survivorship statistics, 2012. CA Cancer J Clin. 2012;62(4):220-241.

62. Mishra S, Scherer R, Snyder C, Geigle P, Berlanstein D, Topaloglu O. Exercise interventions on health-related quality of life for people with cancer during active treatment (Review). Cochrane Collab. 2012;8: CD008465.

63. Smits A, Lopes A, Bekkers R, Galaal K. Body mass index and the quality of life of endometrial cancer survivors - a systematic review and meta-analysis. Gynecol Oncol. 2015;137(1):180-187.

64. von Gruenigen VE, Waggoner SE, Frasure HE, et al. Lifestyle challenges in endometrial cancer survivorship. Obstet Gynecol. 2011; 117(1):93-100.

65. Lauver D, Connolly-Nelson K, Vang P. Health-related goals in female cancer survivors after treatment. Cancer Nurs. 2007;30(1):9-15.

66. Rossi A, Moadel-Robblee A, Garber CE, et al. Physical activity for an ethnically diverse sample of endometrial cancer survivors: a needs assessment and pilot intervention. J Gynecol Oncol. 2015;26(2):141-147. 
67. Neff R, McCann GA, Carpenter KM, et al. Is bariatric surgery an option for women with gynecologic cancer? Examining weight loss counseling practices and training among gynecologic oncology providers. Gynecol Oncol. 2014;134(3):540-545.

68. Beavis AL, Cheema S, Holschneider CH, Duffy EL, Amneus MW. Almost half of women with endometrial cancer or hyperplasia do not know that obesity affects their cancer risk. Gynecol Oncol Rep. 2015; 13:71-75.

69. Tseng JH, Long Roche K, Jernigan AM, Salani R, Bristow RE, Fader AN. Lifestyle and weight management counseling in uterine cancer survivors: a study of the uterine cancer action network. Int J Gynecol Cancer. 2015;25(7):1285-1291.

70. von Gruenigen V, Frasure H, Kavanagh MB, et al. Survivors of uterine cancer empowered by exercise and healthy diet (SUCCEED): a randomized controlled trial. Gynecol Oncol. 2012;125(3):699-704.

71. McCarroll ML, Armbruster S, Frasure HE, et al. Self-efficacy, quality of life, and weight loss in overweight/obese endometrial cancer survivors (SUCCEED): a randomized controlled trial. Gynecol Oncol. 2014;132(2):397-402.

72. McCarroll ML, Armbruster S, Pohle-Krauza RJ, et al. Feasibility of a lifestyle intervention for overweight/obese endometrial and breast cancer survivors using an interactive mobile application. Gynecol Oncol. 2015;137(3):508-515.

73. Basen-Engquist K, Carmack C, Brown J, et al. Response to an exercise intervention after endometrial cancer: differences between obese and non-obese survivors. Gynecol Oncol. 2014;133(1):48-55.

74. Nock NL, Dimitropoulos A, Rao SM, et al. Rationale and design of REWARD (revving-up exercise for sustained weight loss by altering neurological reward and drive): a randomized trial in obese endometrial cancer survivors. Contemp Clin Trials. 2014;39(2):236-245.

75. Koutoukidis DA, Knobf MT, Lanceley A. Obesity, diet, physical activity, and health-related quality of life in endometrial cancer survivors. Nutr Rev. 2015;73(6):399-408.

76. Ko EM, Walter P, Jackson A, et al. Metformin is associated with improved survival in endometrial cancer. Gynecol Oncol. 2014;132(2): 438-442.

77. Nevadunsky NS, Van Arsdale A, Strickler HD, et al. Metformin use and endometrial cancer survival. Gynecol Oncol. 2014;132(1):236-240.

78. Al Hilli MM, Bakkum-Gamez JN, Mariani A, et al. The effect of diabetes and metformin on clinical outcomes is negligible in risk-adjusted endometrial cancer cohorts. Gynecol Oncol. 2016;140(2):270-276.

79. Hall C, Stone RL, Gehlot A, Zorn KK, Burnett AF. Use of metformin in obese women with type I endometrial cancer is associated with a reduced incidence of cancer recurrence. Int J Gynecol Cancer. 2016;26(2): 313-317.

80. ClinicalTrials.gov [webpage on the Internet]. Paclitaxel and Carboplatin With or Without Metformin Hydrochloride in Treating Patients with Stage III, IV, or Recurrent Endometrial Cancer; 2014 [updated July 13, 2015]. Available from: https://clinicaltrials.gov/ct2/show/NC T02065687?term $=$ endometrial + cancer + metformin\&rank $=5$. Accessed December 30, 2015.

81. Kotsopoulos J, Baer HJ, Tworoger SS. Anthropometric measures and risk of epithelial ovarian cancer: results from the nurses' health study. Obesity. 2010;18(8):1625-1631.

82. Collaborative Group on Epidemiological Studies of Ovarian Cancer. Ovarian cancer and body size: individual participant meta-analysis including 25,157 women with ovarian cancer from 47 epidemiological studies. PLoS Med. 2012;9(4):e1001200.

83. Zhou Y, Chlebowski R, LaMonte MJ, et al. Body mass index, physical activity, and mortality in women diagnosed with ovarian cancer: results from the Women's Health Initiative. Gynecol Oncol. 2014;133(1): 4-10.

84. Cannioto RA, Moysich KB. Epithelial ovarian cancer and recreational physical activity: a review of the epidemiological literature and implications for exercise prescription. Gynecol Oncol. 2015;137(3): 559-573.
85. Zhong S, Chen L, Lv M, Ma T, Zhang X, Zhao J. Nonoccupational physical activity and risk of ovarian cancer: a meta-analysis. Tumour Biol. 2014;35(11):11065-11073.

86. Bertone ER, Rosner BA, Hunter DJ, et al. Dietary fat intake and ovarian cancer in a cohort of US women. Am J Epidemiol. 2002;156(1): 22-31.

87. Crane TE, Khulpateea BR, Alberts DS, Basen-Engquist K, Thomson CA Dietary intake and ovarian cancer risk: a systematic review. Cancer Epidemiol Biomarkers Prev. 2014;23(2):255-273.

88. Xie J, Poole EM, Terry KL, et al. A prospective cohort study of dietary indices and incidence of epithelial ovarian cancer. J Ovarian Res. 2014 7:112.

89. Chandran U, Bandera EV, Williams-King MG, et al. Healthy eating index and ovarian cancer risk. Cancer Causes Control. 2011;22(4): 563-571.

90. $\mathrm{Hu} \mathrm{J}, \mathrm{Hu} \mathrm{Y,} \mathrm{Hu} \mathrm{Y,} \mathrm{Zheng} \mathrm{S.} \mathrm{Intake} \mathrm{of} \mathrm{cruciferous} \mathrm{vegetables} \mathrm{is}$ associated with reduced risk of ovarian cancer: a meta-analysis. Asia Pac J Clin Nutr. 2015;24(1):101-109.

91. Han B, Li X, Yu T. Cruciferous vegetables consumption and the risk of ovarian cancer: a meta-analysis of observational studies. Diagn Pathol. 2014;9:7.

92. Liu J, Tang W, Sang L, et al. Milk, yogurt, and lactose intake and ovarian cancer risk: a meta-analysis. Nutr Cancer. 2014;67(1): 68-72.

93. Jiang $P$, Jiang Z, Shen K, Yue Y. Fish intake and ovarian cancer risk: a meta-analysis of 15 case-control and cohort studies. PLoS One. 2014;9(4):e94601.

94. Braem MGM, Onland-Moret NC, Schouten LJ, et al. Coffee and tea consumption and the risk of ovarian cancer: a prospective cohort study and updated meta-analysis. Am J Clin Nutr. 2012;95(5): 1172-1181.

95. Gosvig CF, Kjaer SK, Blaakær J, Høgdall E, Høgdall C, Jensen A. Coffee, tea, and caffeine consumption and risk of epithelial ovarian cancer and borderline ovarian tumors: results from a Danish case-control study. Acta Oncol (Madr). 2015;54(8): 1144-1151.

96. Oppeneer SJ, Robien K. Tea consumption and epithelial ovarian cancer risk: a systematic review of observational studies. Nutr Cancer. 2011;63(6):817-826

97. Cassidy A, Huang T, Rice MS, Rimm EB, Tworoger SS. Intake of dietary flavonoids and risk of epithelial ovarian cancer. Am J Clin Nutr. 2014;100(5):1344-1351.

98. Gao M, Ma W, Chen X-B, Chang Z-W, Zhang X-D, Zhang M-Z. Meta-analysis of green tea drinking and the prevalence of gynecological tumors in women. Asia Pac J Public Health. 2013;25 (4 suppl):43S-48S.

99. Tasevska N, Jiao L, Cross AJ, et al. Sugars in diet and risk of cancer in the NIH-AARP Diet and Health Study. Int J Cancer. 2012;130(1): 159-169.

100. Silvera SAN, Jain M, Howe GR, Miller AB, Rohan TE. Glycaemic index, glycaemic load and ovarian cancer risk: a prospective cohort study. Public Health Nutr. 2007;10(10):1076-1081.

101. King MG, Olson SH, Paddock L, et al. Sugary food and beverage consumption and epithelial ovarian cancer risk: a population-based case-control study. BMC Cancer. 2013;13:94

102. Yan-Hong H, Jing L, Hong L, Shan-Shan H, Yan L, Ju L. Association between alcohol consumption and the risk of ovarian cancer: a metaanalysis of prospective observational studies. BMC Public Health. 2015;15:223

103. Kelemen LE, Bandera EV, Terry KL, et al. Recent alcohol consumption and risk of incident ovarian carcinoma: a pooled analysis of 5,342 cases and 10,358 controls from the Ovarian Cancer Association Consortium. BMC Cancer. 2013;13:28.

104. Rota M, Pasquali E, Scotti L, et al. Alcohol drinking and epithelial ovarian cancer risk. A systematic review and meta-analysis. Gynecol Oncol. 2012;125(3):758-763. 
105. Tworoger SS, Gertig DM, Gates MA, Hecht JL, Hankinson SE. Caffeine, alcohol, smoking, and the risk of incident epithelial ovarian cancer. Cancer. 2008;112(5):1169-1177.

106. Beral V, Gaitskell K, Hermon C, Moser K, Reeves G, Peto R. Ovarian cancer and smoking: individual participant meta-analysis including 28,114 women with ovarian cancer from 51 epidemiological studies. Lancet Oncol. 2012;13(9):946-956.

107. Faber MT, Kjær SK, Dehlendorff C, et al. Cigarette smoking and risk of ovarian cancer: a pooled analysis of 21 case-control studies. Cancer Causes Control. 2013;24(5):989-1004.

108. Li D-P, Du C, Zhang Z-M, et al. Breastfeeding and ovarian cancer risk: a systematic review and meta-analysis of 40 epidemiological studies. Asian Pac J Cancer Prev. 2014;15(12):4829-4837.

109. Feng L-P, Chen H-L, Shen M-Y. Breastfeeding and the risk of ovarian cancer: a meta-analysis. J Midwifery Womens Health. 2014;59(4): 428-437.

110. Rice MS, Murphy MA, Tworoger SS. Tubal ligation, hysterectomy and ovarian cancer: a meta-analysis. J Ovarian Res. 2012;5(1):13.

111. Walker JL, Powell CB, Chen L-M, et al. Society of Gynecologic Oncology recommendations for the prevention of ovarian cancer. Cancer. Epub 2015 Mar 27.

112. Marchetti C, De Felice F, Palaia I, et al. Risk-reducing salpingooophorectomy: a meta-analysis on impact on ovarian cancer risk and all cause mortality in BRCA 1 and BRCA 2 mutation carriers. BMC Womens Health. 2014;14:150.

113. Beral V, Doll R, Hermon C, Peto R, Reeves G; Collaborative Group on Epidemiological Studies of Ovarian Cancer. Ovarian cancer and oral contraceptives: collaborative reanalysis of data from 45 epidemiological studies including 23,257 women with ovarian cancer and 87,303 controls. Lancet. 2008;371(9609):303-314.

114. Lurie G, Thompson P, McDuffie KE, Carney ME, Terada KY, Goodman MT. Association of estrogen and progestin potency of oral contraceptives with ovarian carcinoma risk. Obstet Gynecol. 2007;109(3):597-607.

115. Wilailak S, Vipupinyo C, Suraseranivong V, et al. Depot medroxyprogesterone acetate and epithelial ovarian cancer: a multicentre case-control study. BJOG. 2012;119(6):672-677.

116. Urban M, Banks E, Egger S, et al. Injectable and oral contraceptive use and cancers of the breast, cervix, ovary, and endometrium in black South African women: case-control study. PLoS Med. 2012;9(3):e1001182.

117. Depot-medroxyprogesterone acetate (DMPA) and risk of epithelial ovarian cancer. The WHO Collaborative Study of Neoplasia and Steroid Contraceptives. Int J Cancer. 1991;49(2):191-195.

118. Liang AP, Levenson AG, Layde PM, et al. Risk of breast, uterine corpus, and ovarian cancer in women receiving medroxyprogesterone injections. JAMA. 1983;249(21):2909-2912.

119. Huang Z, Gao Y, Wen W, et al. Contraceptive methods and ovarian cancer risk among Chinese women: a report from the Shanghai Women's Health Study. Int J Cancer. 2015;137(3):607-614.

120. Dorjgochoo T, Shu X-O, Li H-L, et al. Use of oral contraceptives, intrauterine devices and tubal sterilization and cancer risk in a large prospective study, from 1996 to 2006. Int J Cancer. 2009;124(10): 2442-2449.

121. Shu XO, Brinton LA, Gao YT, Yuan JM. Population-based casecontrol study of ovarian cancer in Shanghai. Cancer Res. 1989;49(13): $3670-3674$.

122. Anderson GL, Judd HL, Kaunitz AM, et al. Effects of estrogen plus progestin on gynecologic cancers and associated diagnostic procedures. JAMA. 2003;290(13):1739.

123. Rossouw JE, Anderson GL, Prentice RL, et al. Risks and benefits of estrogen plus progestin in healthy postmenopausal women: principal results From the Women's Health Initiative randomized controlled trial. JAMA. 2002;288(3):321-333.

124. Beral V, Gaitskell K, Hermon C, Moser K, Reeves G, Peto R. Menopausal hormone use and ovarian cancer risk: individual participant meta-analysis of 52 epidemiological studies. Lancet. 2015;385(9980): $1835-1842$.
125. Danforth KN, Tworoger SS, Hecht JL, Rosner BA, Colditz GA, Hankinson SE. A prospective study of postmenopausal hormone use and ovarian cancer risk. Br J Cancer. 2006;96(1):151-156.

126. Lavie O, Pinchev M, Rennert HS, Segev Y, Rennert G. The effect of statins on risk and survival of gynecological malignancies. Gynecol Oncol. 2013;130(3):615-619.

127. Robinson E, Nandi M, Wilkinson LL, Arrowsmith DM, Curtis ADM, Richardson A. Preclinical evaluation of statins as a treatment for ovarian cancer. Gynecol Oncol. 2013;129(2):417-424.

128. Pinheiro SP, Tworoger SS, Cramer DW, Rosner BA, Hankinson SE. Use of nonsteroidal antiinflammatory agents and incidence of ovarian cancer in 2 large prospective cohorts. Am J Epidemiol. 2009; 169(11):1378-1387.

129. Cook NR, Lee I-M, Gaziano JM, et al. Low-dose aspirin in the primary prevention of cancer: the Women's Health Study: a randomized controlled trial. JAMA. 2005;294(1):47-55.

130. Trabert B, Ness RB, Lo-Ciganic W-H, et al. Aspirin, nonaspirin nonsteroidal anti-inflammatory drug, and acetaminophen use and risk of invasive epithelial ovarian cancer: a pooled analysis in the Ovarian Cancer Association Consortium. J Natl Cancer Inst. 2014;106(2):djt431.

131. Ni X, Ma J, Zhao Y, Wang Y, Wang S. Meta-analysis on the association between non-steroidal anti-inflammatory drug use and ovarian cancer. Br J Clin Pharmacol. 2013;75(1):26-35.

132. Baandrup L, Faber MT, Christensen J, et al. Nonsteroidal antiinflammatory drugs and risk of ovarian cancer: systematic review and meta-analysis of observational studies. Acta Obstet Gynecol Scand. 2013;92(3):245-255.

133. Murphy MA, Trabert B, Yang HP, et al. Non-steroidal anti-inflammatory drug use and ovarian cancer risk: findings from the NIH-AARP Diet and Health Study and systematic review. Cancer Causes Control. 2012;23(11):1839-1852.

134. Bodmer M, Becker C, Meier C, Jick SS, Meier CR. Use of metformin and the risk of ovarian cancer: a case-control analysis. Gynecol Oncol. 2011;123(2):200-204

135. Shah MM, Erickson BK, Matin T, et al. Diabetes mellitus and ovarian cancer: more complex than just increasing risk. Gynecol Oncol. 2014;135(2):273-277.

136. Nagle CM, Dixon SC, Jensen A, et al. Obesity and survival among women with ovarian cancer: results from the Ovarian Cancer Association Consortium. Br J Cancer. 2015;113(5):817-826.

137. Smits A, Smits E, Lopes A, et al. Body mass index, physical activity and quality of life of ovarian cancer survivors: time to get moving? Gynecol Oncol. 2015;139(1):148-154.

138. von Gruenigen VE, Frasure HE, Jenison EL, Hopkins MP, Gil KM. Longitudinal assessment of quality of life and lifestyle in newly diagnosed ovarian cancer patients: the roles of surgery and chemotherapy. Gynecol Oncol. 2006;103(1):120-126.

139. Mizrahi D, Naumann F, Broderick C, Samara J, Ryan M, Friedlander M. Quantifying physical activity and the associated barriers for women with ovarian cancer. Int J Gynecol Cancer. 2015;25(4):577-583.

140. Mizrahi D, Broderick C, Friedlander M, et al. An exercise intervention during chemotherapy for women with recurrent ovarian cancer: a feasibility study. Int J Gynecol Cancer. 2015;25(6): 985-992.

141. Stevinson C, Faught W, Steed H, et al. Associations between physical activity and quality of life in ovarian cancer survivors. Gynecol Oncol. 2007;106(1):244-250.

142. Beesley VL, Price MA, Butow PN, Green AC, Olsen CM, Webb PM. Physical activity in women with ovarian cancer and its association with decreased distress and improved quality of life. Psychooncology. 2011;20(11):1161-1169.

143. Hwang K-H, Cho O-H, Yoo Y-S. The effect of comprehensive care program for ovarian cancer survivors. Clin Nurs Res. Epub 2014 Nov 26.

144. Moonsammy SH, Guglietti CL, Santa Mina D, et al. A pilot study of an exercise \& cognitive behavioral therapy intervention for epithelial ovarian cancer patients. J Ovarian Res. 2013;6(1):21. 
145. von Gruenigen VE, Frasure HE, Kavanagh MB, Lerner E, Waggoner SE, Courneya KS. Feasibility of a lifestyle intervention for ovarian cancer patients receiving adjuvant chemotherapy. Gynecol Oncol. 2011;122(2): 328-333.

146. Newton MJ, Hayes SC, Janda M, et al. Safety, feasibility and effects of an individualised walking intervention for women undergoing chemotherapy for ovarian cancer: a pilot study. BMC Cancer. 2011; 11:389.

147. Paxton RJ, Garcia-Prieto C, Berglund M, et al. A randomized parallelgroup dietary study for stages II-IV ovarian cancer survivors. Gynecol Oncol. 2012;124(3):410-416.

148. Thomson CA, E Crane T, Wertheim BC, et al. Diet quality and survival after ovarian cancer: results from the Women's Health Initiative. J Natl Cancer Inst. 2014;106(11):dju314.

149. ClinicalTrials.gov [webpage on the Internet]. Diet and Physical Activity Change or Usual Care in Improving Progression-Free Survival in Patients With Previously Treated Stage II, III, or IV Ovarian, Fallopian Tube, or Primary Peritoneal Cancer; 2008 [updated July 13, 2014]. Available from: https://clinicaltrials.gov/ct2/show/NCT00719303? term $=\% 22$ ovarian + cancer $\% 22+$ diet\&recr=Open\&rank=3. Accessed September 25, 2015.

150. Li D, Ding C, Qiu L. Postoperative hormone replacement therapy for epithelial ovarian cancer patients: a systematic review and metaanalysis. Gynecol Oncol. 2015;139(2):355-362.
151. Eeles RA, Morden JP, Gore M, et al. Adjuvant hormone therapy may improve survival in epithelial ovarian cancer: results of the AHT randomized trial. J Clin Oncol. 2015;33(35):4138-4144.

152. Neff R, Havrilesky LJ, Chino J, O'Malley DM, Cohn DE. Bariatric surgery as a means to decrease mortality in women with type I endometrial cancer - an intriguing option in a population at risk for dying of complications of metabolic syndrome. Gynecol Oncol. 2015; 138(3):597-602.

153. ClinicalTrials.gov [webpage on the Internet]. Feasibility Study: Therapeutic Targeting of Stress Factors in Ovarian Cancer Patients; 2012 [updated November 3, 2015]. Available from: https://clinicaltrials. gov/show/NCT01504126. Accessed January 6, 2016.

154. Fallowfield L, Fleissig A, Barrett J, et al. Awareness of ovarian cancer risk factors, beliefs and attitudes towards screening: baseline survey of 21,715 women participating in the UK Collaborative Trial of Ovarian Cancer Screening. Br J Cancer. 2010;103(4):454-461.

155. Bui KT, Wakefield CE, Kasparian NA, Tyler J, Abbott J, Tucker K. Oral contraceptive use in women at increased risk of breast/ovarian cancer: knowledge and attitudes. Psychooncology. 2013;22(1):228-232.

156. Donnelly CM, Blaney JM, Lowe-Strong A, et al. A randomised controlled trial testing the feasibility and efficacy of a physical activity behavioural change intervention in managing fatigue with gynaecological cancer survivors. Gynecol Oncol. 2011;122(3):618-624.
International Journal of Women's Health

\section{Publish your work in this journal}

The International Journal of Women's Health is an international, peerreviewed open-access journal publishing original research, reports, editorials, reviews and commentaries on all aspects of women's healthcare including gynecology, obstetrics, and breast cancer. The manuscript management system is completely online and includes

\section{Dovepress}

a very quick and fair peer-review system, which is all easy to use. Visit http://www.dovepress.com/testimonials.php to read real quotes from published authors. 